\title{
Issues in (inter)professionalism
}

\author{
Geoff Norman
}

Received: 17 January 2011/Accepted: 17 January 2011/Published online: 15 February 2011

(C) Springer Science+Business Media B.V. 2011

The Reflections article addresses two related, and frequently confused, terms-professionalism and interprofessionalism. Not in so many words: the article focuses on the slightly narrower issue of whether ethics should be taught and learned in interprofessional settings. The authors conclude that, while learning about other professions is better accomplished in interprofessional courses (a fairly self-evident truth), the specific learning of ethics related to patient care may be better accomplished within specific disciplines.

Such a conclusion might be viewed as heretical by some. Interprofessional education is usually viewed as a "good thing" and ethics would appear to be an ideal area for interprofessional learning, since the issues and concepts of ethics would appear to transcend disciplinary boundaries. As Caldicott and Braun say:

There is much to gain by encouraging mutual respect across professions in the resolution of moral dilemmas. In a joint ethics class, an imaging student and a medical student could discuss their differing professional roles and learn to analyze competing values and priorities... This setting may encourage caretakers to become more confident in challenging the views of others - including superiors or members of other disciplines - when ethical dilemmas arise.

They ultimately conclude that there are clear advantages for both interprofessional and single-professional courses. That implies a clear separation between learning ethics as one aspect of learning about professionalism and learning about other professions. In my experience, however, these two areas are often confounded. To clarify this distinction I wish to pursue two questions:

(1) What is the fundamental basis of "professionalism?

(2) What are the essential competencies to be mastered in interprofessional education?

Although I cannot pretend to be an expert in this area, I would like to share a few thoughts.

G. Norman $(\bowtie)$

MDCL 3519, McMaster University, 1200 Main St. W, Hamilton, ON, Canada

e-mail: norman@mcmaster.ca 
First, with regard to professonalism. Years and years ago I took a course at Michigan State University on "Professions and Organizations". At the time, I viewed it as a "bird" course to round out my quota and get an easy mark, but of little value in my intended carer path in research. Wrong on all counts. It was hard, but it became invaluable. And I learned some basic ideas about the nature of professions that still hold me in good stead. Maybe these are so fundamental that everyone already knows the answer, so let me do a pretest of your knowledge. Answer the following question:

Why are a physiatrist (rehabilitation medicine) and a pharmacist professionals, but a plumber, a physicist and a pharmacologist not professionals?

The answer follows from two fundamental and historical characteristics. To be a professional, one must have a specialized body of knowledge (which rules out plumbers, by and large) and an autonomous client relationship (which rules out physicists and pharmacologists). Everything else is a consequence of these two fundamental aspects. Clients cannot judge the specialized knowledge, so professions evolved guilds and specialty societies, licensing bodies, accreditation bodies, and examinations, all to the goal of ensuring that the professional was competent, since the client could not. On this basis, some traditional "professionals" are ruled out (soldiers, airmen), and some unlikely people, like the anonymous individual at the end of the computer helpline, sitting in a booth anywhere in the world, may be ruled in. (So, by the way, are statisticians, when our advice is sought by researchers. Perhaps we should have licensing examinations too.). This basic idea is consistent with the approach taken by Cruess et al. (2004) in their carefully argued definition.

This definition has some far-reaching implications. In particular, some things that are often viewed as essential to the professional, such as relating well to other professionals, however desirable, are not central to the nature of the profession. On the other hand, innovations like practice guidelines and computer decision aids can be seen to be eroding the nature of the profession, since they remove some aspect of judgment from the professional.

And now to interprofessionalism. To me, the central question is this:Is interprofessionalism a state of mind or attitude, general skill, general knowledge, or specific knowledge? That is, does it amount to demonstrating respect and appreciation for individuals in other professions? Or are there some skills one can acquire from working with other professionals and by extension, from studying with students in other professions? Are there things (knowledge, skills attitudes) that must be acquired by observing and interacting with other health professionals in a health care setting like a palliative care team or an emergency room? And do these things generalize to other settings so that experience in a palliative care team leads to more efficient and effective interactions in an operating room or ICU? Or is it really all about going into each multiprofessional setting and beginning de novo to learn the specific skills the nurse, physiotherapist or pharmacist, brings to this setting?

Perhaps the answers to these questions are now well established. Certainly my occasional ventures into this area suggest that we re moving to a perspective on interprofessionalism that is closer to the latter than the former. If so, this has strong implications for the nature of educational experiences that are created to foster interprofessional skills. It is not sufficient to arrange educational events where students from various professions meet and study together; such events might be viewed as "aprofessional". Rather, the curriculum must include multiple specific interprofessional experiences in different health care settings such as described by Kuper and D'Eon (2011). 


\section{References}

Cruess, S. R., Johnston, S., \& Cruess, R. L. (2004). "Profession": A working definition for medical educators. Teaching and Learning in Medicine, 16, 74-76.

Kuper, A., \& D'Eon, M. (2011). Rethinking the basis of medical knowledge. Medical Education, 45, 36-43. 